blackbirds have precious little in common beyond sharing an ultimate common ancestor. The evolutionary line of the mammals can be traced back to the paramammals, but this is not a sound basis for terming the mammallike reptiles 'mammals', nor for including the mammals in the Paramammalia. The fact that we can now begin to indicate lines of descent is not a licence to redraft the classification.

The conclusions drawn by Desmond run far ahead of the available evidence. A great deal more work will be required before such notions of dinosaur endothermy can be taken seriously. Ther $\epsilon$ can be little doubt, however, that the dinosaurs were warm-blooded. The dinosaurs achieved a passive type of homoiothermy by being large; their surface-volume ratio would have ensured a fairly constant internal temperature. All the features that have been used to attribute endothermy to the dinosaurs can more easily be interpreted as being a direct consequence of their size.

It is a pity that Desmond's undoubted literary talents were not used in a more deserving cause than promoting hot-blooded dinosaurs.

\section{Conceptual shorthand}

Transport Phenomena in Medicine and Biology. By M. Min-Shing Lih. Pp. xviii +531. (Wiley-Interscience: New York and London, 1975.) £14.70. THIS book gives a very clear presentation of the mathematics necessary to describe-with a fair degree of rigour -the underlying physics involved in physiological processes concerned with transport of mass, momentum and energy. The author is to be complimented on achieving his declared aim of demonstrating how the mathematical conceptual 'shorthand' of physics can reduce the apparent phenomenological diversity of physiology. From the start the emphasis is on translation from the real world to the mathematical model, solution of the problem and back to the real world to present the answer in physical terms. The mathematics is continuously related to reality so that an experimentalist has his interest maintained and is carried along with the argument. This is done in a direct and refreshingly conversational way, producing more the flavour of a verbatim record of a colloquium than a concise university text.

With such a discursive style the author does well to contain his subject within 500 pages. The first five chapters present the mathematics necessary for a proper description of material processes in terms of con-

\title{
Synaptic receptors
}

approach, whereas most other work has concentrated on the former. Recently,

Synaptic Receptors: Isolation Molecular Biology. (Modern Pharmacology-Toxicology : A Series of Monographs and Textbooks.) By Eduardo de Robertis. Pp. xiv + 387. (Dekker : New York, 1975.) \$29.50.

IN those synapses with chemical transmission, the transmitter substance acts on the postsynaptic membrane by combination with synaptic receptors. Within the last ten years, our knowledge of these receptors has advanced from a condition in which their existence as discrete structures was far from established to a situation in which several have been isolated. Their isolation is the subject of Dr de Robertis' book.

Synaptic receptors, as constituents of membranes, are amphipathic and there are, broadly speaking, two approaches to their isolation. The first uses detergents in aqueous solution to counteract their hydrophobicity and effect solubilisation. The second approach seeks to take advantage of this hydrophobicity by extracting receptors into nonaqueous solvents of low polarity. Dr de Robertis has played a dominant role in the development of the latter

tinuum physics. Chapters 6,7 and 8 show us how to apply the mathematics to changing conditions as diverse as pulsatile blood flow, body heat loss, placenta mass transport and gastric acid analysis. Chapters 9 and 10 are specifically dedicated to haemorrheology-the non-Newtonian behaviour of blood as a suspension of cells flowing through narrow vessels-and oxygen transport. This last chapter is an impressive discussion of a vital process, including examples of varied problem solving from membrane blood oxygenators to the oxygen-tension profile in the cornea.

We are told that the original manuscript was 'test-used' in a Chatauquatype programme, and I would agree that the final book is very well suited for this self-help with guidance type of learning. The comprehensive presentation of 'Mathematical Background' in Chapter 2 makes the book self-contained. The reader is taken from functions and variables (p16) through to the tensor and its operations (p96), and by this time is ready to accept quite naturally the need for a tensor as a description of the stress on an element of fluid. I particularly liked the use of small print flow diagrams to illustrate on one page a single application of the mathematics being discussed. All of the mathematical development is integrated with the rest of the book through the use of
Barrantes et al. (Nature, 256, 325-327,

1975) have shown that, at least in the case of the acetylcholine receptor, there is nothing in common between the material isolated by these two methods. This casts a long shadow over the book, for in spite of a superficial balance, it is, in fact, an apologia for $\mathrm{Dr}$ de Robertis. This should surprise no one for Dr de Robertis' prolificity is truly remarkable, having isolated some half dozen receptors from twice as many tissues.

The need for an expensive monograph at the present time is open to the strongest doubt, more so since Dr de Robertis has displayed the virtue of brevity in a subsequent review covering the same ground (Rev. Physiol. Biochem. Pharmac., 73, 9-38; 1975). The book contains a quite incredible number of typographical errors from the merely irritating to the downright misleading.

Until such time as our knowledge of synaptic receptors enables distinction between the permanently valuable and the ephemeral, a book of this kind is prey to premature obsolescence and, at the price, just not worth it.

David Green

\section{problems.}

Because of the excellent integration I wondered if it might not be difficult to easily 'dip' and use parts of the book as a companion text in an undergraduate course-say haemodynamics. For example, the pursuit of generality in the development of the mathematical models means that to arrive at a particular point such as the description of pulsatile flow in a pipe seemed to be longer than Womersley's direct approach. The very applied flavour, however, of the maths makes the attempt an attractive/worthwhile proposition. Certainly I have not found any more suitable text for that type of course.

Some of the material in this book will be familiar to any teacher in this field and even the organisation may in part be already in use. Yet the whole achievement of keeping the practical biomedical quality of the mathematics always so apparent makes this a most welcome book. It will certainly be a great help in courses at final special honours or MSc level in this country. Although the fly-leaf suggests it is an ideal text for the student I do not believe that it is an easy book for the unaided beginner. For the postgraduate student and the biomedical researcher it should handsomely repay the investment of time necessary to come to terms with this very able and challenging presentation.

R. G. Gosling 